\title{
À LUZ DA LAMPARINA: A JORNADA DO HERÓI NO CONTO POPULAR
}

IN THE LIGHT OF THE LAMP: HERO'S JOURNEY IN THE POPULAR TALE

\author{
Cacio José Ferreira ${ }^{1}$
}

\begin{abstract}
RESUMO: Este artigo trata de algumas considerações sobre a jornada do herói e sua ressonância no inconsciente por meio da história $O$ bicho de um olho só contada por Domingos Samuel Xavier Guimarães, morador do Sudeste do Tocantins. As histórias orais nos permitem a reconstrução de valores e a visualização das experiências regionais nelas depositadas. Nessa perspectiva, o texto discute, também, a simbologia presente na narrativa, a natureza harmoniosa com a comunidade na qual se insere por meio da transmissão de ensinamentos e valores que servem para toda a vida, mas que passam despercebidas pelos interlocutores. As narrativas fazem resplandecer o mundo, as eras, os tempos, as pessoas, a dor e a alegria em um só espaço. Transferem e preenchem o espaço que o contador e o ouvinte precisam para seguir os passos e destinos do herói.
\end{abstract}

Palavras-chave: História popular; Narrativa oral; Simbologia; Inconsciente; Jornada do herói.

ABSTRACT: This article deals with some considerations about the journey of the hero and his resonance in the unconscious through the story $O$ bicho de um olho só told by Domingos Samuel Xavier Guimarães, a resident of Southeastern Tocantins. Oral histories allow us to reconstruct values and visualize the regional experiences deposited in them. In this perspective, the text also discusses the symbology present in the narrative, the harmonious nature with the community in which it is inserted through the transmission of teachings and values that serve for all of life, but that go unnoticed by the interlocutors. The narratives make the world, the ages, the times, the people, the pain and the joy in one space shine. They transfer and fill in the space that the accountant and the listener need to follow the steps and destinies of the hero.

Keywords: Popular history; Oral narrative; Symbology; Unconscious; Hero's Journey.

Há muito tempo o homem busca decifrar os enigmas do mundo por meio da busca pelo conhecimento. A metáfora da lamparina, recheada de combustível e mantendo o pavio aceso contra as trevas noturnas, refere-se à luz que ilumina o inconsciente. $O$ contar

\footnotetext{
${ }^{1}$ Professor Assistente da Universidade Federal do Amazonas (UFAM). E-mail: caciosan@ hotmail.com
} 
e recontar de uma história atravessa oceanos e cristaliza em diversos lugares incorporando as verdades locais.

Nesse viés, a força descomunal dos Ciclopes - gigantes monstruosos de um olho destacado na fronte - nasce nos mitos da Grécia antiga. Essas formas primitivas de força são chamadas de demônios da tempestade, pois o olho único representava o relâmpago (BRANDÃO, 2003). Os Ciclopes se distinguem em três espécies: Os Urânios - filhos de Úrano e Géia, os Sicilianos - companheiros de Polifemo - imortalizado na Odisseia de Homero, canto IX, e os Construtores. Sobre essas distinções, Brandão postula:

Os primeiros, Brontes, Estéropes e Arges são os urânios. Encadeados pelo pai, foram a pedido de Géia, libertados por Crono, mas por pouco tempo. Temendo-os, este os lançou novamente no Tártaro, até que, advertido por um oráculo de que não poderia vencer os Titãs sem o concurso dos Ciclopes, Zeus os libertou definitivamente. Estes agradecidos deram-lhe o trovão, o relâmpago e o raio. A Plutão ou Hades ofereceram um capacete que podia torná-lo invisível e a Posídon, o tridente. Foi assim, como se verá, que os Olímpicos conseguiram derrotar os Titãs (BRANDÃO, 1987, p. 204).

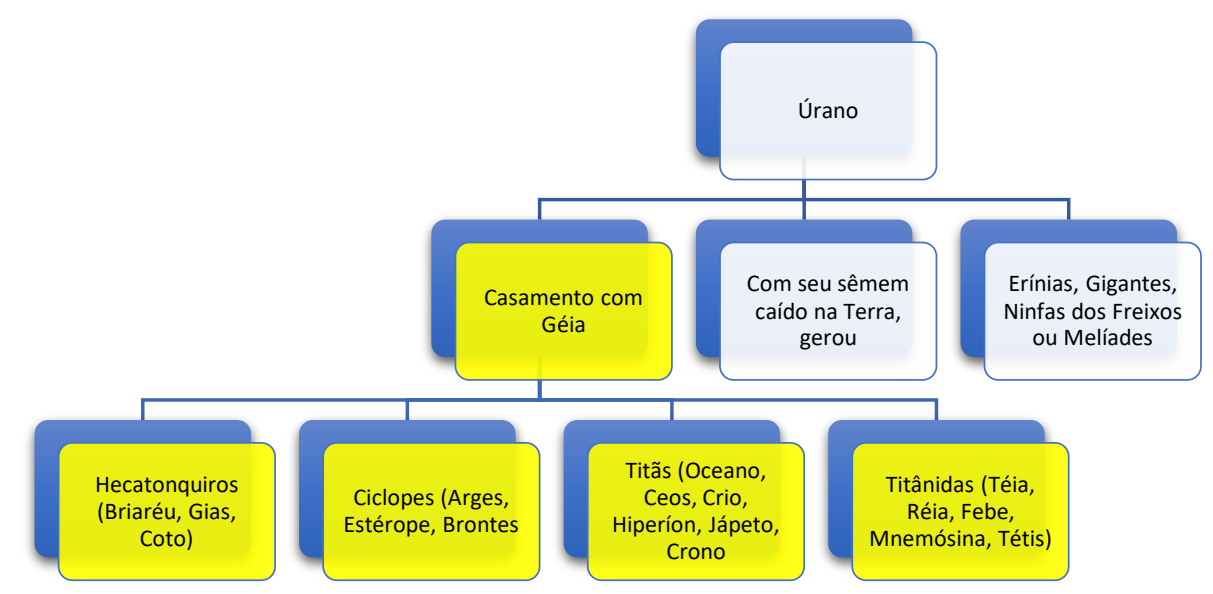

Imagem I

Os Sicilianos - incorporados aos segundos grupos de Ciclopes - eram selvagens, antropófagos e possuidores de uma força quase divina, habitavam em cavernas e possuíam pequenos rebanhos de ovelhas ${ }^{2}$. No terceiro grupo mesmo apresentando

\footnotetext{
${ }^{2} \mathrm{Na}$ narrativa irlandesa, a ovelha tem um simbolismo maléfico e diabólico. Segundo o dicionário de símbolos, "os druidas perversos do rei Cormac, rei da Irlanda, em luta contra a província de Münster,
} 
elevado grau de maldade, os Ciclopes Sicilianos/Homéricos foram se aperfeiçoando e dominando pequenas tecnologias: eram ferreiros em oficinas subterrâneas e construtores de todas as armas dos deuses. "De antropófagos se transmutaram, na erudita poesia alexandrina, em frágeis seres humanos, mordidos por Eros" (BRANDÃO, 1987, p. 205).

\section{Imagem II}

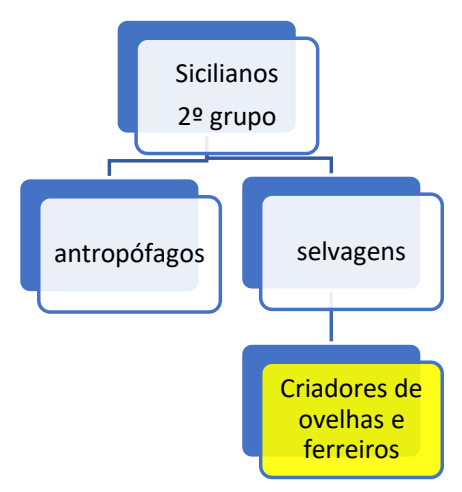

Longe da Grécia, uma versão ciclópica aparece na fábula tocantinense $O$ bicho de um olho só ${ }^{3}$, contada por Domingos Samuel Xavier Guimarães, morador da cidade interiorana de Altamira, sudeste do Tocantins. A história contada narra a aventura de dois irmãos que chegaram ao reino de um ser de um olho só, criador de ovelhas e assassino com requintes de crueldade. A narrativa inicia-se da seguinte forma:

Dois homens estavam na beira do mar a procura de água mais fina pra beber. Aí encontraram com bicho de um olho só. Ele mandou que eles entrassem no meio do rebanho das ovelhas. Seguiram, então, rumo à moradia do bicho, na toca lá na serra (Trecho de $O$ bicho de um olho só).

O chamado para a transformação do herói se dá a partir de uma necessidade: a procura de água pura para beber. O chamado pode acontecer, segundo Campbell, de várias formas - às vezes os heróis seguem a estrada do destino. O caminho a ser seguido

utilizavam três ovelhas negras, malvadas, cobertas de espetos de ferro, que derrotavam os guerreiros". (CHEVALIER, 2008, p. 672).

\footnotetext{
${ }^{3}$ A história no anexo do texto bem como partes citadas ao longo do texto considera em grande parte a linguagem oral do narrador.
} 
é predestinado, ou ainda, tornam-se heróis por força externa: algum monstro invade a vila e destrói a casa dos pais, o dragão que sequestra a princesa e o herói deixa o lar para resgatá-la, cumprindo seu destino. O anti-herói desloca o protagonista por meio de violência, o obriga a seguir a jornada do herói. Nesse sentido, Campbell argumenta que

[...] um erro - aparentemente um mero acaso - revela um mundo insuspeito, e o indivíduo entra numa relação com forças que não são plenamente compreendidas. Como Freud demonstrou, os erros não são um mero acaso; são, antes, resultado de desejos e conflitos reprimidos. São ondulações na superfície da vida, produzidas por nascentes inesperadas. E essas nascentes podem ser muito profundas - tão profunda quanto a própria alma (CAMPBELL, 2007, p. 60).

A terceira causa de chamado do herói é o acaso, assim como em $O$ bicho de um olho só. Os protagonistas caminham à beira do mar e de repente acontece o início da jornada. O interessante no acaso é a aproximação, de algum modo, do cidadão comum, pois poderia acontecer com qualquer indivíduo. O herói não é semideus ou predestinado, mas tem uma missão a cumprir, o contrário de Hércules, por exemplo. O narrador fala de gente comum, assim como ele, sendo herói. O chamado se dá de maneira emergencial, surge uma necessidade: eles estão com sede. Não há um grau de violência assim como acontece, por exemplo, quando a crueldade de um rei destrói a vila e intima o herói a agir.

Na história contada por Domingos Samuel Xavier Guimarães, a partir de uma ótica simbólica, temos dois protagonistas e a simbologia do inconsciente. Eles estão em um lugar de fronteira, com desejo de aventura e de conhecimento. Ter sede significa que há uma vontade de contatar-se com o inconsciente. Eles "estavam à beira do mar a procura de água mais fina pra beber'. É necessário encarar o oceano ainda que perigoso, pois ele apresenta a face destruidora, que engole, afoga, e é incomensurável. Ainda assim, ali os dois heróis o enfrenta em busca de revelação, do conhecimento puro. O mar representa nesse cenário o

[...] símbolo dinâmico da vida. Tudo sai do mar e tudo retorna a ele: lugar do nascimento, das transformações e dos renascimentos. Águas em movimento, o mar simboliza um estado transitório entre as 
possibilidades ainda informes as realidades configuradas, uma situação de ambivalência, que é a incerteza, de dúvida, de indecisão, e pode se concluir bem ou mal (CHEVALIER, 2008, p. 592).

Os heróis querem acessar o inconsciente, mas o contato profundo representado pelo mar é perigoso. Qual seria o remédio ideal? Um meio termo pode ser a resposta. Eles podem saciar a sede sem arriscar se perderem nas profundezas do oceano. Em solo os perigos existem, mas há firmeza de pontos já conhecidos. A consciência se coloca numa situação perigosa pela descida ao inconsciente. Não houve e nem eles tinham uma preparação completa para o embate absoluto, então buscam um meio termo: água mais transparente e menos riscos.

Ao encontrarem o bicho de um olho só, não conseguem defini-lo como uma figura única. $\mathrm{O}$ bicho era o monstro? $\mathrm{O}$ antagonista? $\mathrm{O}$ inimigo? Em termos junguianos, o monstro era a sombra, o lado negativo da personalidade, o lado inferior, sem valor, primitivo da natureza do homem. Ele é também a "outra pessoa" em um indivíduo, seu próprio lado obscuro:

[...] todo mundo carrega uma sombra, e quanto menos ela está incorporada na vida consciente do indivíduo, mais negra e densa ela é. Se uma inferioridade é consciente, sempre se tem uma oportunidade de corrigi-la. Além do mais, ela está constantemente em contato com outros interesses, de modo que está continuamente sujeita a modificações. Porém, se é reprimida e isolada da consciência, jamais é corrigida, e pode irromper subitamente em um momento de inconsciência. De qualquer modo, forma um obstáculo inconsciente, impedindo nossos mais bem-intencionados propósitos $\left(\mathrm{CW}^{4} 11, \S 131\right.$ APUD SAMUELS, 1988, p. 204).

O antagonista, por sua vez, assume a forma de um deus mensageiro, de Mercúrio, o mutável: “[...] Ele mandou que eles entrassem no meio do rebanho das ovelhas. Seguiram, então, rumo à moradia do bicho, na toca lá na serra. Chegou lá e abriu a porta que era uma pedra enorme. Tirou lentamente a pedra da porta e entrou. Em

\footnotetext{
${ }^{4}$ Collected Works of C. G. Jung.
} 
seguida, ordenou que entrassem lá. Eles entraram”. É líquido e metal ao mesmo tempo. Consegue ir ao alto do Olimpo e descer às profundezas da terra por meio de sua ambiguidade, do não lugar. A capacidade de assumir formas diversas e, contudo, permanecer ele próprio, é o que exige a mudança psicológica. "Jung descreve tal ato como a terceira parte da aliança. O seu lado enfurecido e diabólico é equilibrado por suas propensões transformadoras. Para os alquimistas, mercúrio é, a um mesmo e só tempo, mau, vil, duvidoso e divino" (SAMUELS, 1988, p. 25). O bicho de um olho só abre caminhos para os irmãos, faz-se guia e mensageiro. É por meio dessa monstruosidade que os heróis entram em contato com as formas mais profundas do inconsciente, e o acesso é permitido a partir de um ser com qualidades negativas - o guardião das fronteiras e do conhecimento. Começa definitivamente a jornada do herói:

[...] a aventura é, sempre e em todos os lugares, uma passagem pelo véu que separa o conhecido do desconhecido; forças que vigiam no limiar são perigosas e lidar com elas envolve riscos; e, no entanto, todos os que têm competência e coragem verão o perigo desaparecer (CAMPBELL, 2007, p. 85).

O inconsciente enfrentado pelos heróis é simultaneamente perigoso e transformador. Assume o poder de converter o chumbo em ouro, o carvão em diamante. Esse ser é provocador de mudança, possuidor de força. É o fluxo contínuo e sem volta. Os heróis não seguem mais um caminho construído de vontade própria, mas são guiados por uma força que anula. A partir do momento que encontra o monstro, o caminho não tem volta. Esse caminho sem retorno é o momento da transformação. Adentrar na caverna significa entrar na mãe, voltar ao seio materno, simbolizando mais uma vez a mudança, o que é absorvido ou se coloca no seio da terra, transforma-se. A semente se torna árvore, o homem se torna pó, há transmutação. Há dois fatores que conduzem os heróis ao renascimento: o bicho de um olho só como mensageiro e a terra como local gerador de renovação. Jonas foi gerado profeta dentro do ventre da baleia: "Então o Senhor deparou com um grande peixe, para que tragasse a Jonas; e esteve Jonas três dias e três noites nas entranhas do peixe" (Jonas, 1,17). 
Até a chegada à caverna, o antagonista estava atrás dos heróis e das ovelhas. $\mathrm{O}$ guia não segue sempre à frente? Isso significa equivaler ao segundo lugar, não representando, porém, importância maior que a dos heróis, embora ao mesmo tempo consiga manter controle quase absoluto do local em que estava. Essa função dupla de um aparente segundo plano reforça a posição de poder, controle e conhecimento por parte do ciclope (inconsciente). O pastor conhece quase tudo sobre o rebanho. No momento em que o eixo roda, ele toma a dianteira e abre a porta do limiar manifestando seu poder de guia. A prova começa para o herói. O herói sabe que o processo de transformação começou e tem receio dos perigos que enfrentará durante a provação:

[...] a provação é um aprofundamento do problema do primeiro limiar e a questão ainda está em jogo: pode o ego entregar-se a morte? Pois muitas cabeças têm essa Hidra circundante; cortada uma delas, duas outras se formam - exceto se for aplicado, ao coto mutilado, o cauterizador apropriado. A partida original para a terra das provas representou, tão-somente, o início da trilha, longa e verdadeiramente perigosa, das conquistas da iniciação e dos momentos de iluminação. Cumpre agora matar dragões e ultrapassar surpreendentes barreiras repetidas vezes. Enquanto isso, haverá uma multiplicidade de vitórias preliminares, êxtases que não se podem reter e relances momentâneos da terra das maravilhas (CAMPBELL, 2007, p. 110).

Essa descida ao fundo da terra, algo semelhante ao inferno, mas dentro de si mesmo, é apaziguada e envolvida pelo som da viola. O som designa um crescimento individual nos momentos de provação do herói. A percepção auditiva também é uma forma de construção do conhecimento. Chevalier postula que "o som é percebido antes da forma, a audição é anterior à visão" (CHEVALIER, 2008, p. 842), assim como Orfeu com a sua lira sedutora atravessa o limiar e chega aos redutos infernais.

O bicho de um olho só quando solicita ao homem que toque a viola demonstra traços humanos - dispõe de linguagem porque sempre há uma ordem que impera. Além disso, é engenhoso, inventor e possui conhecimentos matemáticos. A construção de uma viola exige maestria, sofisticação, uma técnica extremamente fina. $O$ fato de ele ter ali na caverna um instrumento de arte e apreciar essa arte demonstra sua humanização. 
A expressão "Ele tinha um espeto muito grande encostado na parede. Depois de certo tempo, ele pegou o espeto e pegou um dos homens e o espetou vivo e a coivarona ${ }^{5}$ de fogo ardia em chamas. Em seguida, tacou ele no fogo e começou a assá-lo" reforça a ideia de poder do inconsciente. Há mesmo uma figura um tanto paterna, o pai ogro, monstro, perigoso, devorador, assustador que precisa ser derrotado. É comum a criança, ao atravessar o complexo de Édipo, construa um pai com essas características, assim como o herói que enfrenta diversas dificuldades. O papel paternal é concebido como

[...] desencorajador dos esforços de emancipação, exercendo uma influência que priva, limita, esteriliza, mantém na dependência. Ele representa a consciência diante dos impulsos instintivos, dos desejos espontâneos, do inconsciente; é o mundo da autoridade tradicional diante das forças novas de mudança (CHEVALIER, 2008, p. 678).

O pai, ameaçador, não hesitou em demonstrar todo o seu poder: "Em seguida, tacou ele no fogo e começou a assá-lo. Depois gritou com o outro continuar a tocar a viola enquanto o assado ficava pronto". A crueldade e a civilização caminham lado a lado nessa metáfora alquímica de transformação. Chama a atenção o fato de o monstro esperar para comer. A barbárie convivendo com traços civilizados é um dos principais estágios na transmutação de um animal em homem, pois para a humanização acontecer é preciso que se proíba o incesto, o canibalismo e o homicídio. Para Claude Lévi-Strauss, o domínio do fogo significa poder assar a carne, passar do estado cru para o cozido, sendo denominado, por ele, de "representações míticas da passagem da natureza à cultura"6. $\mathrm{O}$ autor sugere que os mitos de $O$ cru e o cozido enfatizam uma fisiologia da aliança matrimonial, mantendo a culinária como metáfora do andamento harmonioso da sociedade e do cosmos. Os ritos, os sacrifícios, as festas são como novas experiências da mesma mitologia. "O pensamento mítico, totalmente alheio a pontos de partida ou

\footnotetext{
${ }^{5}$ Amontoado de galhos de árvores e arbustos que são separados para se atear fogo.

${ }^{6}$ LÉVI-STRAUSS, Claude. O cru e o cozido. Mitológicas 1. São Paulo, Cosac Naify, 2004.
} 
chegada bem definidos, não efetua percursos completos: sempre lhe resta algo a perfazer" (LÉVI-STRAUSS, 2004, p. 24).

"Depois gritou com o outro continuar a tocar a viola enquanto o assado ficava pronto. "Como é que se diverti vendo o irmão no espeto assando?”. Mesmo apreciando a arte musical, o antagonista sugere que o som da viola é para anestesiar o herói que será seu banquete futuro. É um requinte de crueldade do monstro. O herói, ao ver o irmão no espeto, enxerga a si mesmo. Eles representam um duplo, que é uno, o aspecto dual de tudo. Toda essa aventura, a jornada inteira do herói pode ser interpretada como uma única pessoa tentando conhecer a si mesma, valendo-se de uma linguagem simbólica, metafórica. O processo de encontro e embate com o inconsciente é doloroso. Existe uma morte no caminho. $\mathrm{O}$ indivíduo que começa a jornada morre durante o trajeto, mas esse caminho que sugere morte também é ressurreição. O sofrimento demasiado regenera e transforma.

O antagonista, com dúbia humanização, seguia como provocador das provações do herói: “Quando o assado ficou pronto, comeu uma porção e o que sobrou colocou no espeto novamente e foi deitar". O monstro também é muito ambíguo. Apresenta traços primitivos e sofisticados. Isso prova que ele é um ser do limiar, de fronteira. Não se pode afirmar que ele é apenas um monstro. Ele se fixa no meio: pode descer ao útero da terra ou subir para a superfície. Ele é o consciente e o inconsciente.

O local de transformação, o inconsciente, configura a metáfora de um grande cemitério a abrigar todos os defeitos, traumas, pessoas que o herói já teve, além de arrependimentos e segredos que o consciente não conhece. O herói, ao tramar a volta para a casa, faz um pacto e entra no jogo do inconsciente.

[...] "Disse que havia muito couro de ovelha, né?". O bicho deitou e caiu em sono profundo "O bicho de um olho só". O rebanho de ovelha estava quietinho. $\mathrm{O}$ outro homem espantando pensava no que poderia fazer para fugir dali. Não tinha pra onde saí. Quem abria a porta era só o bicho, pois era muito pesada. O bicho estava dormindo. Olhou para os quatro cantos e não havia nenhuma saída. No entanto, astuto como era, descobriu o que fazer. Ele tirou o resto do irmão do espeto e o bicho continuava a dormir. Ele tem um só olho e eu vou furar ele para que fique cego. Então, pegou o espeto e fincou no olho do bicho. Ele 
levantou aos gritos sem saber o que fazer. Assim, meteu a mão e arrancou o espeto do olho jogou pra lá e saiu doido procurando a porta. Até quem abria a porta era só ele. No entanto, o homem sobrevivente antes dele fazer esse serviço com o monstro, pegou um coro de ovelha e amarrou nas costas. Quando a porta foi aberta, o homem foi saindo de quatro pés junto com as ovelhas (Trecho de O bicho de um olho só).

A mutação de homem em ovelha - quando este usa o resto mortal - significa nivelar-se ao animal, pois é passível de ser comido como eles. A consciência sabe que essa mutação é a única maneira de vencer o poder do inconsciente. O herói se transforma parcialmente, pois ainda está ciente dos riscos que corre. Ele sabe que, caso se deixe seduzir totalmente pelo inconsciente, será engolido por ele. Então, mantém controle e procura executar os artifícios planejados. O desespero, o pavor e o grito podem acordar o monstro - por isso, o herói sobreviveu por causa do raciocínio lógico e do autocontrole. O fingimento de que faz o jogo do inconsciente permite ao herói alargar sua percepção e dá a ele uma vantagem para sobrevivência. O inconsciente é incapaz de ter raciocínio lógico, pois opera sempre com base na contradição não possui ideia de tempo e só pode ser vencido pelo conhecimento, apesar de perigoso.

A inteligência do herói aproveitou um descuido, um despreparo, uma vulnerabilidade do inconsciente para tentar se salvar. O ego conhece a zona do perigo e sabe o tamanho do território desconhecido. Por isso, usou de artimanhas para enfrentar a sombra. Encarar o inconsciente é cair no abismo sem fim. Ele usa a seu favor pele da ovelha, o poder depositado no espeto, que são armas do inconsciente. A inteligência venceu a força. A ideia é valorizar a civilização e não a barbárie. Essa história é contada pelo ego para si mesmo. Transmite a mensagem de que há maior força quando o raciocínio é utilizado.

O monstro ciclópico tem um olho só, conta a história. Segundo o dicionário de símbolos, o número um

é o princípio. Apesar de não manifestado, é dele que emana toda manifestação e é a ele que ela retorna, esgotada a sua existência efêmera. O um é o local simbólico do ser, fonte e fim de todas as coisas, centro cósmico e ontológico. Símbolo do ser, mas também da Revelação, que é mediadora para elevar o homem, através do 
conhecimento, a um nível superior. O um é também o centro místico, de onde irradia-se o Espírito como um sol (CHEVALIER, 2008, p. 918).

O herói, antes duplo, torna-se um único sujeito, podendo assumir toda a energia e a harmonia do consciente e do inconsciente. Ele se unifica atingindo, desse modo, a totalidade. Irracional e racional, imaginário e real, côncavo e convexo se conjugam ao herói desenvolvendo-o plenamente. Assim está pronto para enfrentar a nova vida após o retorno.

O bicho de um olho só ficou com a mão passando sobre o pelo das ovelhas. Se o homem passasse andando, ele gazapiava ${ }^{7}$. O monstro só sentiu o pelo das ovelhas passando na mão. Aí saiu e tocô no mundo! Chegou à embarcação correndo muito. $\mathrm{O}$ bicho já estava na beira do mar. O sobrevivente entrou na embarcação e vazou no mundo. E o bicho ficou lá na beira do mar aos berros. Disse que não tinha só um. Havia mais. Na hora que gritou, disseram que juntou foi uma enorme quantidade deles. Inconformado, os bichos jogavam cada pedra pra ver se acertava o barco matava o homem, mas ele conseguiu fugir (Trecho da fábula $O$ bicho de um olho só).

Pronto para o retorno? Uma provocação direta do inconsciente significa a loucura, psicologicamente. A profunda confusão que o herói experimentou, a verdade total na qual imergiu fez sua regeneração. Assim como a luta travada na fábula entre homem e monstro, a narrativa oral vai e volta. A fluidez da oralidade, do inconsciente, da memória não demarca tempo. Não há passado ou futuro, tudo é presente. Essa miscelânea de provas não fez o herói anular-se na figura monstruosa e nem deixar de existir. A consciência se antecipou ao inconsciente e saiu junto com as ovelhas.

Ao final da fábula, percebe-se a inteligência tanto do homem como do monstro. O herói usou a pele da ovelha para se disfarçar e o monstro se mostrou hábil ao usar a mão como meio de percepção. O herói retorna renovado ao seu lar. Para Campbell, "a

\footnotetext{
${ }^{7}$ Segurava, pegava com força.
} 
fuga é um episódio favorito do conto folclórico, no qual é desenvolvida sob muitas formas vívidas" (CAMPBELL, 2007, p. 199). Se o herói obtiver, em seu triunfo, "a benção da deusa ou do deus e for explicitamente encarregado de retornar ao mundo com algum elixir destinado à restauração da sociedade, o estágio final de sua aventura será apoiado por todos os poderes do seu patrono sobrenatural" (CAMPBELL, 2007, p.198).

Desse modo, o herói mantém uma relação com o mar do início ao fim da história, mas ele só é capaz de enfrentá-lo e lidar com o inconsciente depois de toda a provação feita durante o caminho do herói. Transformou, adquiriu maturidade, conhecimento. Esse processo de individuação, descrito por Jung, é a transformação da pessoa em si mesma, sem contradição, indivisível. Apesar da transformação segura e inteira do herói, o inconsciente, na figura humanizada de fronteira, ainda tenta feri-lo, porém sem forças. A transformação já ocorreu.

Portanto, a história $O$ bicho de um olho só revela uma história conhecida do ciclope e do homem que busca alcançar o conhecimento puro, obtido a partir de devaneios e sonhos misteriosos do inconsciente. Bachelard (2002) resume essa procura pela essência social do saber:

O sonhador isolado guarda em particular valores oníricos ligados à linguagem; guarda a poesia própria da linguagem de sua raça. As palavras que ele aplica às coisas poetizam as coisas, valorizam-nas espiritualmente num sentido que não pode fugir completamente das tradições. O poeta mais inovador que explora o devaneio mais livre dos hábitos sociais transporta para os seus poemas. [...] É preciso compreender que o sonho é uma força da natureza. Não se pode conhecer a pureza sem sonhá-la. Não se pode sonhá-la força sem verlhe a marca, a prova, a substância na natureza (BACHELARD, 2002, p. 141).

As histórias orais nos permitem a reconstrução de valores e a carga de experiências regionais nelas depositadas. Ainda que suas impressões sejam marcadas, por vezes, por várias influências dos antepassados, são essas memórias que revelam o caráter, a necessidade, o pensamento tranquilo e observador do narrador que brinca com os acontecimentos da vida. Não à toa guardam muito afinidade com a região, com a natureza 
em uma harmoniosa integração com a comunidade na qual se insere. Transmitem lições de moral, bem como ensinamentos e valores que servem para toda a vida, mas que passam despercebidas pelos interlocutores. As narrativas fazem resplandecer o mundo, as eras, os tempos, as pessoas, a dor e a alegria em um só espaço. Transferem e preenchem o espaço que o contador e o ouvinte precisam para seguir seus passos e destinos.

\section{REFERÊNCIAS}

BACHELARD, Gaston. A Água e os sonhos: ensaio sobre a imaginação da matéria. São Paulo: Martins Fontes, 2002. . A Poética do espaço. São Paulo: Abril, 1988.

BENJAMIM, Walter. Magia e técnica, arte e política: ensaios sobre a literatura e história da cultura. Obras escolhidas. São Paulo, Brasiliense, 1994.

BRANDÃO, Junito de Souza. Mitologia Grega. Petrópolis: Vozes, 1987.

BRUNEL, Pierre. Dicionários de Mitos Literários. Tradução de Carlos Sussekind, Jorge Laclette, Maria Thereza e Vera Whately. Rio de Janeiro: José Olympio, 2005.

CAMPBELL, Joseph. O herói de mil faces. São Paulo: Pensamento, 2007.

O poder do mito. São Paulo, Palas Athena, 2005.

CHEVALIER, Jean \& GHEERBRANT, Alain. Dicionário de Símbolos. Tradução de Vera da Costa e Silva. Rio de Janeiro: José Olympio, 2008.

COELHO, Nelly Novaes. O conto de fadas: símbolos - mitos - arquétipos. São Paulo: Paulinas, 2008.

ELIADE, Mircea. Imagens e Símbolos: ensaio sobre o simbolismo mágico - religioso. São Paulo: Fontes, 1991.

FRYE, Northrop. Fábulas de identidade - estudos de mitologia poética. Tradução: Sandra Vasconcelos. São Paulo: Nova Alexandria, 1999.

GUIMARÃES, Domingos Samuel Xavier. O bicho de um olho só. Contador da narrativa oral.

HALL, Calvin S. \& NORDBY, Vernon J. Introdução à Psicologia Junguiana. São Paulo: Cultrix, 1993. 
Revista Água Viva

JUNG, Carl Gustav. Psicologia e alquimia. Petrópolis: Vozes, 1990.

JOLLES, André. Formas Simples. São Paulo: Cultrix, 1976.

LÉVI-STRAUSS, Claude. O cru e o cozido. Mitológicas 1. São Paulo: CosacNaify, 2004.

PROPP, V. I. Morfologia do conto maravilhoso. Tradução de Jasna Paravich Sarhan. Rio de Janeiro: Forense Universitária, 2006.

SAMUELS, Andrew. Dicionário crítico de análise junguiana. Tradução de Pedro Ratis e Silva. Rio de Janeiro: Imago, 1988.

THOMPSON, Paul. A voz do passado: história oral. Rio de Janeiro: Paz e Terra, 2002.

Recebido em: 20 abr. 2018

Aceito em: 19 mai. 2018 


\section{ANEXO}

\section{O bicho de um olho só ${ }^{8}$}

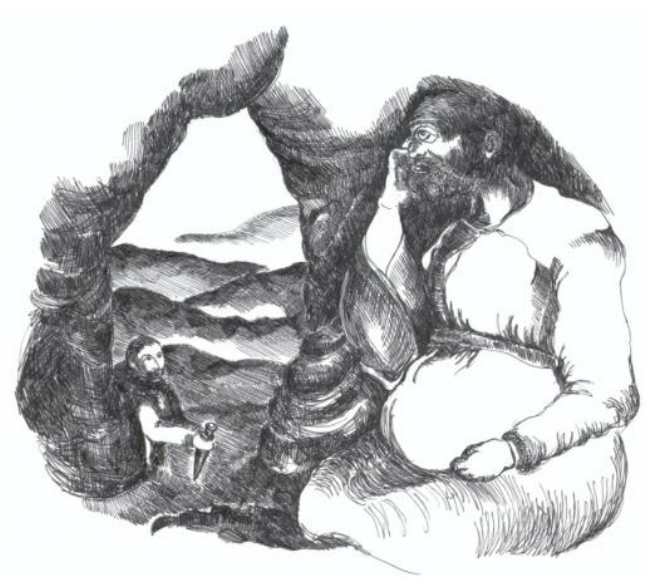

ois homens estavam na beira do mar a procura de água mais fina pra beber. Aí encontraram com bicho de um olho só. Ele mandou que eles entrassem no meio do rebanho das ovelhas. Seguiram, então, rumo à moradia do bicho, na toca lá na serra. Chegou lá e abriu a porta que era uma pedra enorme. Tirou lentamente a pedra da porta e entrou. Em seguida, ordenou que entrassem lá. Eles entraram. O bicho deu uma viola para que um deles tocasse. Obedecendo a sentença, sentou em um banquinho e começou tocá-la. Ele tinha um espeto muito grande encostado na parede. Depois de certo tempo, ele pegou o espeto e pegou um dos homens e o espetou vivo e a coivarona ${ }^{9}$ de fogo ardia em chamas. Em seguida, tacou ele no fogo e começou a assá-lo. Depois gritou com o outro continuar a tocar a viola enquanto o assado ficava pronto. "Como é que se diverti vendo o irmão no espeto assando?”. Quando o assado ficou pronto, comeu uma porção e o que sobrou colocou no espeto novamente e foi deitar. "Disse que havia muito couro de ovelha, né?”. O bicho deitou e caiu em sono profundo. “O bicho de um olho só". O rebanho de ovelha estava quietinho. O outro homem espantando

\footnotetext{
${ }^{8}$ Contada por Domingos Samuel Xavier Guimarães.

${ }^{9}$ Amontoado de galhos de árvores e arbustos que são separados para se atear fogo.
} 
pensava no que poderia fazer para fugir dali. Não tinha pra onde saí. Quem abria a porta era só o bicho, pois era muito pesada. O bicho estava dormindo. Olhou para os quatro cantos e não havia nenhuma saída. No entanto, astuto como era, descobriu o que fazer. Ele tirou o resto do irmão do espeto e o bicho continuava a dormir. Ele tem um só olho e eu vou furar ele para que fique cego. Então, pegou o espeto e fincou no olho do bicho. Ele levantou aos gritos sem saber o que fazer. Assim, meteu a mão e arrancou o espeto do olho jogou pra lá e saiu doido procurando a porta. Até quem abria a porta era só ele. No entanto, o homem sobrevivente antes dele fazer esse serviço com o monstro, pegou um coro de ovelha e amarrou nas costas. Quando a porta foi aberta, o homem foi saindo de quatro pés junto com as ovelhas. O bicho de um olho só ficou com a mão passando sobre o pelo das ovelhas. Se o homem passasse andando, ele gazapiava ${ }^{10}$. O monstro só sentiu o pelo das ovelhas passando na mão. Aí saiu e tocô no mundo! Chegou à embarcação correndo muito. O bicho já estava na beira do mar. O sobrevivente entrou na embarcação e vazou no mundo. E o bicho ficou lá na beira do mar aos berros. Disse que não tinha só um. Havia mais. Na hora que gritou, disseram que juntou foi uma enorme quantidade deles. Inconformado, os bichos jogavam cada pedra pra ver se acertava o barco matava o homem, mas ele conseguiu fugir.

${ }^{10}$ Segurava, pegava com força. 